\title{
Impact of age and comorbidities on health-related quality of life for patients with prostate cancer: evaluation before a curative treatment
}

\author{
Michael Pinkawa*1, Karin Fischedick¹, Bernd Gagel1, Marc D Piroth ${ }^{1}$, \\ Branka Asadpour ${ }^{1}$, Jens Klotz ${ }^{1}$, Holger Borchers ${ }^{2}$, Gerhard Jakse ${ }^{2}$ and \\ Michael J Eble ${ }^{1}$
}

Address: ${ }^{1}$ Department of Radiation Oncology, RWTH Aachen University, Pauwelsstrasse 30, 52057 Aachen, Germany and ${ }^{2}$ Department of Urology, RWTH Aachen University, Pauwelsstrasse 30, 52057 Aachen, Germany

Email: Michael Pinkawa* - mpinkawa@ukaachen.de; Karin Fischedick - kfischedick@ukaachen.de; Bernd Gagel - bgagel@ukaachen.de; Marc D Piroth - mpiroth@ukaachen.de; Branka Asadpour - basadpour@ukaachen.de; Jens Klotz - jklotz@ukaachen.de; Holger Borchers - hborchers@ukaachen.de; Gerhard Jakse - gjakse@ukaachen.de; Michael J Eble - meble@ukaachen.de

* Corresponding author

Published: 24 August 2009

BMC Cancer 2009, 9:296 doi:10.1 I86/147|-2407-9-296
Received: 14 April 2008

Accepted: 24 August 2009

This article is available from: http://www.biomedcentral.com/I47I-2407/9/296

(c) 2009 Pinkawa et al; licensee BioMed Central Ltd.

This is an Open Access article distributed under the terms of the Creative Commons Attribution License (http://creativecommons.org/licenses/by/2.0), which permits unrestricted use, distribution, and reproduction in any medium, provided the original work is properly cited.

\begin{abstract}
Background: Interpretation of comparative health-related quality of life (HRQOL) studies following different prostate cancer treatments is often difficult due to differing patient ages. Furthermore, agerelated changes can hardly be discriminated from therapy-related changes. The evaluation of age-and comorbidity-related changes was in focus of this study.

Methods: HRQOL of 528 prostate cancer patients was analysed using a validated questionnaire (Expanded Prostate Cancer Index Composite) before a curative treatment. Patients were divided into age groups $\leq 65,66-70,7 /-75$ and $>75$ years. The impact of specific comorbidities and the Charlson Comorbidity Index $(\mathrm{CCl})$ were evaluated. The questionnaire comprises 50 items concerning the urinary, bowel, sexual and hormonal domains for function and bother. For assessment of sexual and hormonal domains, only patients without prior hormonal treatment were included $(n=336)$.

Results: Urinary incontinence was observed increasingly with higher age (mean function scores of 92/88/ $85 / 87$ for patients $\leq 65,66-70,7 /-75$ and $>75$ years) complete urinary control in $78 \% / 72 \% / 64 \% / 58 \%(\mathrm{p}<$ $0.01)$. Sexual function scores decreased particularly $(48 / 43 / 35 / 30)$, with erections sufficient for intercourse in $68 \% / 50 \% / 36 \% / 32 \%(\mathrm{p}<0.0 \mathrm{I})$ a decrease of more than a third comparing patients $\leq 65$ vs. $66-70(36 \%)$ and $66-70$ vs. $71-75$ years (39\%). The percentage of patients with comorbidities was lowest in the youngest group $(48 \%$ vs. $66 \% / 68 \% / 63 \%$ for ages $66-70 / 7 /-75 />75$ years; $p<0.05)$. A multivariate analysis revealed an independent influence of both age and comorbidities on urinary incontinence, specifically diabetes on urinary bother, and both age and diabetes on sexual function/bother. Rectal domain scores were not significantly influenced by age or comorbidities. $\mathrm{A} \mathrm{CCl}>5$ particularly predisposed for lower urinary and sexual HRQOL scores.
\end{abstract}


Conclusion: Urinary continence and sexual function are the crucial HRQOL domains with age-related and independently comorbidity-related decreasing scores. The results need to be considered for the interpretation of comparative studies or longitudinal changes after a curative treatment.

\section{Background}

The number of men diagnosed with localized prostate cancer has increased substantially since the advent of prostate-specific antigen (PSA) testing [1]. The incidence rates stabilized in the last years [2]. Only one randomized study of radical prostatectomy has shown that treatment reduces prostate cancer mortality compared to watchful waiting [3]. Alternatively, external beam irradiation or interstitial brachytherapy is offered frequently [4-8]. Despite advances in the primary treatments, no randomized controlled trial has proven the superiority of one modality in terms of cancer control. In the absence of mortality data, health-related quality of life (HRQOL) evaluations become important outcomes.

Commonly used grading systems are suitable to determine the incidence of most serious side effects, but not the precise significance of problems for HRQOL. Patients are subjectively assessing their problems to be of higher grades compared to the assessment obtained by the physician [9]. Many functions are already impaired before treatment. Important factors are the patient age and comorbidities. Only a minority of HRQOL studies in men with prostate cancer provide some form of comorbidity information [10].

Interpretation of comparative HRQOL studies following different prostate cancer treatments is often difficult due to differing patient ages. Patients receiving external beam radiation therapy are usually slightly older compared to patients receiving brachytherapy, and on average about ten years older compared to patients treated with radical prostatectomy [4-8]. Age-related changes can hardly be discriminated from therapy-related changes in these studies. Not only pre-treatment HRQOL, but additionally natural HRQOL changes can be expected to differ between these patient groups (e.g. changes of a 60 year old compared to a 70 year old patient in the subsequent ten years of life). The aim of this study was to evaluate age-related and comorbidity-related urinary, bowel, sexual and hormonal HRQOL differences of prostate cancer patients before a primary curative treatment.

\section{Methods}

This study was based on 528 consecutive patients who were scheduled for any kind of a curative radiotherapy treatment (external beam irradiation, temporary or permanent brachytherapy) due to $\mathrm{CT} 1-3 \mathrm{~N} 0 \mathrm{M} 0$ prostatic car- cinoma in the years 20032007. All patients answered a validated questionnaire, the Expanded Prostate Cancer Index Composite (EPIC), before the treatment [11]. The questionnaire was handed over to the patients personally by one of the physicians. It comprises 50 items concerning the urinary, bowel, sexual and hormonal domains for function and bother. The multi-item scale scores were transformed lineary to a 0100 scale, with higher scores representing better health-related quality of life. For a detailed analysis, questions in the urinary domain were classified into incontinence and irritation/obstruction subscales $[11,12]$.

Data has been acquired in compliance with the Helsinki Declaration. The evaluation was approved by the local ethics committee. Informed consent was obtained from patients for the treatment. Patients were informed about the voluntary participation in the evaluation of quality of life data. An explicit statement about the voluntary character of the participation was heading every page of the questionnaire.

The EPIC was administered in German. It has been translated in the Department of Radiation Oncology and validated in the department of Medical Psychology and Medical Sociology of our institution [13]. Several studies have been already published [14-20]. These studies very well support the sensitivity of the questionnaire for quality of life changes after treatment in all domains. The relation between individual questions and quality of life scores in different domains as well the correlation of function and bother domains or changes with time have been elaborated in detail. In accordance with data published by Osoba et al. [21], mean HRQOL changes of below 5 points were defined as clinically not significant. For patients who indicated "a little" change, the mean change in scores was about 5 to 10 , for "moderate" change, about 10 to 20; and for "very much" change, greater than 20. The EORTC (European Organization for Research and Treatment of Cancer) QLQ (Quality of Life Questionnaire)C30, evaluated by Osoba et al., uses comparably to the EPIC a 0 to 100 scale. Though the assessment of a clinically significant threshold remains controversial, a 5point threshold proved likewise to be clinically significant in our own experience [14-20].

The group has been divided into the age groups up to 65 $(\mathrm{n}=116), 66-70(\mathrm{n}=144), 71-75(\mathrm{n}=158)$ und $>75$ years 
( $n=110)$ with the aim to discriminate purely age-related health-related quality of life (HRQOL) changes. Five-year increments have been estimated to be relevant intervals with an adequate patient number in each group to detect significant age-related differences. The Charlson Comorbidity Index (CCI) was calculated as a scale that considers both comorbidities and the patient age (starting at 50 years of age, each decade is counted as an extra point) [22].

Neoadjuvant hormonal therapy (NHT) was administered in 192 cases. In a preliminary analysis, mean HRQOL scores were found to be significantly lower in the sexual (function scores: -18 points) and hormonal (function scores: -11 points) domains. Therefore, all evaluations of sexual and hormonal symptoms and scores were limited to the group of patients without NHT ( $n=336$; i.e. prostate cancer not treated with any method before).
Statistical analysis was performed using the SPSS 14.0 (SPSS, Chicago, Ill), software. To explore statistical HRQOL score differences between different subgroups, the Mann-Whitney-U-test was used. Contingency table analysis with the chi-square test was performed to compare treatment groups with respect to categorical variables. In a logistic forward stepwise multivariate analysis, different risk factors were tested for their independence. For the evaluation of age and comorbidities, multivariate analysis was performed twice: 1 . considering age and the presence of any comorbidity; 2 . considering age and various specific comorbidities. As the CCI scale is considering both age and comorbidities, it cannot be considered in this multivariate analysis. Hazard ratios in dependence on the CCI scale were therefore reported separately. The global significance level for all statistical test procedures conducted was chosen as $\alpha=5 \%$. All statistical analyses were conducted in an explorative manner. Thus, with consider-

Table I: Patient characteristics $(n=528)$

\begin{tabular}{|c|c|c|c|c|c|}
\hline & $\leq 65$ years $(n=116)$ & $\begin{array}{l}66-70 \text { years }(n= \\
144)\end{array}$ & $\begin{array}{c}71-75 \text { years }(n= \\
158)\end{array}$ & $>75$ years $(n=110)$ & significant difference \\
\hline $\begin{array}{l}\text { patient age, years } \\
\text { mean } \pm \text { SD; median }\end{array}$ & $62 \pm 4 ; 63$ & $68 \pm 2 ; 68$ & $73 \pm 2 ; 73$ & $78 \pm 2 ; 77$ & all comparisons $(p<0.0 I)$ \\
\hline $\begin{array}{l}\text { prostate volume, cc } \\
\text { mean } \pm \mathrm{SD} \text {; median }\end{array}$ & $42 \pm 20 ; 35$ & $44 \pm 20 ; 39$ & $45 \pm 23 ; 40$ & $46 \pm 21 ; 42$ & - \\
\hline $\begin{array}{l}\mathrm{PSA}<10 \mathrm{ng} / \mathrm{mL} \text {, } \\
\mathrm{n}(\%)\end{array}$ & $66(57)$ & $93(65)$ & $95(60)$ & $55(50)$ & $\begin{array}{c}66-70 \text { vs. }>75 \text { years } \\
(p<0.05)\end{array}$ \\
\hline $\begin{array}{l}\text { biopsy Gleason score <7; } \\
\text { n (\%) }\end{array}$ & $72(62)$ & $90(63)$ & $98(62)$ & $55(50)$ & $\begin{array}{c}66-70 \text { vs. }>75 \text { years } \\
(\mathrm{P}<0.05)\end{array}$ \\
\hline $\begin{array}{l}\text { prior hormonal therapy; } \\
\text { n (\%) }\end{array}$ & $46(40)$ & $50(35)$ & $55(35)$ & $4 \mid(37)$ & - \\
\hline $\begin{array}{l}\text { comorbidities; } \\
\text { n (\%) }\end{array}$ & $56(48)$ & $95(66)$ & $108(68)$ & $69(63)$ & $\begin{array}{c}\leq 65 \text { vs. } 66-70 / 71-75 />75 \\
\text { years }(p<0.05)\end{array}$ \\
\hline $\begin{array}{l}\text { hypertension; } \\
\text { n (\%) }\end{array}$ & $24(2 I)$ & $44(31)$ & $53(34)$ & $27(25)$ & $\begin{array}{l}\leq 65 \text { vs. } 71-75 \text { years } \\
(p<0.05)\end{array}$ \\
\hline $\begin{array}{l}\text { coronary heart disease; } \\
\text { n (\%) }\end{array}$ & $17(15)$ & $29(20)$ & $43(27)$ & $30(27)$ & $\begin{array}{c}\leq 65 \text { vs. } 71-75 />75 \text { years } \\
(p<0.05)\end{array}$ \\
\hline $\begin{array}{l}\text { diabetes; } \\
\text { n (\%) }\end{array}$ & $13(11)$ & $16(11)$ & $17(11)$ & $16(15)$ & - \\
\hline $\begin{array}{l}\text { COPD; } \\
\text { n (\%) }\end{array}$ & $7(6)$ & $13(9)$ & $17(11)$ & $12(11)$ & - \\
\hline $\begin{array}{l}\mathrm{CCl}<5 / 5 />5 \\
\text { n }(\%)\end{array}$ & $86 / 17 / 13(74 / 15 / 11)$ & $\begin{array}{c}69 / 49 / 26 \\
(48 / 34 / 18)\end{array}$ & $\begin{array}{l}0 / 85 / 73 \\
(0 / 54 / 46)\end{array}$ & $\begin{array}{l}0 / 47 / 63 \\
(0 / 43 / 57)\end{array}$ & $\begin{array}{l}\text { for all }(p<0.01) \text {, with } \\
\text { exception } 71-75 \text { vs. }>75\end{array}$ \\
\hline
\end{tabular}

SD: standard deviation; PSA: prostate specific antigen; COPD: chronic obstructive pulmonary disease; CCl: Charlson Comotbidity Index 
ation of the explorative character of the analysis, p-values $<0.05$ can be interpreted as statistically significant test results.

\section{Results}

Patient characteristics (Table 1) demonstrate a well balanced distribution of a prior hormonal therapy over the different age groups. The prostate volume was slightly increasing with the patient age. The highest percentage of tumors with a PSA $\geq 10 \mathrm{ng} / \mathrm{mL}$ and a Gleason score $\geq 7$ was found in the oldest age group. The percentage of patients with at least a single comorbidity was lowest in the youngest age group (significant difference in comparison to all other age groups) four of the most frequent comorbidities are listed additionally in Table 1 . The CCI demonstrates highly significant differences. Patients older than 70 years reached at least five points due to their age (three points) and the diagnosis of prostate cancer (two points).

Urinary incontinence was observed increasingly with higher age; urinary bother scores decreased. Sexual function scores fell most impressively, but sexual bother scores did not change as markedly (Table 2 ). The results of some individual questions demonstrating significant changes with increasing patient ages are presented in Figures 1, 2, 3 and 4 (only tendencies in the hormonal domain). Some ability to have an erection remains even in the oldest age group, but in only $32 \%$ firm enough for sexual intercourse. The percentage of patients with erections firm enough for sexual intercourse decreased more than a third comparing patients up to 65 vs. $66-70$ years $(36 \%)$ and 66-70 vs. $71-75$ years (39\%), respectively. Even clearer than the different age groups, a CCI>5 was particularly predisposing for significantly lower urinary function/ bother (including both continence and irritation/obstruction) and lower sexual function/bother scores (Table 3).

The presence of even a single comorbidity was associated with decreased HRQOL scores (Table 4). A mean decrease of at least 5 points has not been observed in the rectal domain. Parallel with a higher patient age, decreasing scores associated with a comorbidity were found for the urinary continence function, urinary bother (specifically coronary heart disease and diabetes) and sexual function (strong impact of diabetes). A contrary effect resulted in the hormonal domain decreasing scores associated with coronary heart disease and COPD, but increasing scores associated with age.

Table 2: Function and bother scores (mean \pm standard deviation; median) in dependence on age group

\begin{tabular}{|c|c|c|c|c|}
\hline & $\leq 65$ years & $66-70$ years & $7 I-75$ years & $>75$ years \\
\hline urinary function & $94 \pm 13 ; 100$ & $92 \pm 15 ; 100$ & $91 \pm 14 ; 100$ & $92 \pm 12 ; 94$ \\
\hline continence function* & $92 \pm 18 ; 100$ & $88 \pm 21 ; 100$ & $85 \pm 23 ; 100$ & $87 \pm 20 ; 94$ \\
\hline irritative/obstructive function & $95 \pm 13 ; 100$ & $97 \pm 12 ; 100$ & $98 \pm 10 ; 100$ & $98 \pm 9 ; 94$ \\
\hline urinary botherf & $82 \pm 20 ; 89$ & $84 \pm 20 ; 91$ & $82 \pm 18 ; 89$ & $79 \pm 19 ; 86$ \\
\hline continence bother & $93 \pm 22 ; 100$ & $90 \pm 25 ; 100$ & $90 \pm 25 ; 100$ & $90 \pm 22 ; 100$ \\
\hline irritative/obstructive bother & $80 \pm 20 ; 90$ & $83 \pm 20 ; 90$ & $81 \pm 18 ; 85$ & $79 \pm 18 ; 83$ \\
\hline bowel function & $91 \pm 11 ; 96$ & $93 \pm 9 ; 96$ & $93 \pm 9 ; 96$ & $93 \pm 9 ; 96$ \\
\hline bowel bother & $93 \pm 14 ; 100$ & $93 \pm 14 ; 100$ & $95 \pm 10 ; 100$ & $93 \pm 13 ; 100$ \\
\hline sexual function $\ddagger$ & $48 \pm 25 ; 50$ & $43 \pm 23 ; 50$ & $35 \pm 23 ; 32$ & $30 \pm 24 ; 28$ \\
\hline sexual bother & $68 \pm 32 ; 75$ & $64 \pm 34 ; 75$ & $56 \pm 36 ; 56$ & $60 \pm 33 ; 63$ \\
\hline hormonal function§ & $88 \pm 17 ; 100$ & $91 \pm 16 ; 100$ & $92 \pm 13 ; 100$ & $95 \pm 10 ; 100$ \\
\hline hormonal bother & $89 \pm 16 ; 96$ & $91 \pm 15 ; 100$ & $92 \pm 14 ; 96$ & $94 \pm 11 ; 100$ \\
\hline
\end{tabular}

*significant difference $\leq 65$ vs. $71-75 />75$ years $(p<0.01)$

† significant difference $66-70$ vs. $>75$ years $(p<0.01)$

$\ddagger$ significant difference $\leq 65$ vs. $7 \mathrm{I}-75 />75$ and $66-70$ vs. $71-75 />75$ years $(\mathrm{p}<0.01)$

$\S$ significant difference $\leq 65$ vs. $>75$ years $(p=0.03)$ 
Table 3: Function and bother scores (mean \pm standard deviation; median) in dependence on Charlson Comorbidity Index (CCI)

\begin{tabular}{|c|c|c|c|}
\hline $\mathrm{CCl}$ & $<5$ & 5 & $>5$ \\
\hline urinary function* & $94 \pm 12 ; 100$ & $93 \pm 12 ; 100$ & $89 \pm 16 ; 94$ \\
\hline continence function* & $92 \pm 17 ; 100$ & $90 \pm 18 ; 100$ & $82 \pm 25 ; 100$ \\
\hline irritative/obstructive function & $97 \pm 12 ; 100$ & $97 \pm 9 ; 100$ & $96 \pm 13 ; 100$ \\
\hline urinary bother* & $85 \pm 19 ; 93$ & $84 \pm 16 ; 89$ & $77 \pm 22 ; 82$ \\
\hline continence bother* & $93 \pm 20 ; 100$ & $93 \pm 20 ; 100$ & $86 \pm 29 ; 100$ \\
\hline irritative/obstructive bother* & $84 \pm 19 ; 90$ & $83 \pm 16 ; 85$ & $76 \pm 21 ; 80$ \\
\hline bowel function & $93 \pm 9 ; 96$ & $93 \pm 8 ; 96$ & $91 \pm 10 ; 96$ \\
\hline bowel bother & $94 \pm 13 ; 100$ & $94 \pm 11 ; 100$ & $92 \pm 15 ; 100$ \\
\hline sexual function* & $49 \pm 22 ; 5 I$ & $37 \pm 24 ; 37$ & $31 \pm 24 ; 29$ \\
\hline sexual bother & $68 \pm 31 ; 75$ & $64 \pm 34 ; 69$ & $52 \pm 36 ; 50$ \\
\hline hormonal function & $92 \pm 14 ; 100$ & $90 \pm 13 ; 100$ & $90 \pm 13 ; 100$ \\
\hline hormonal bother & $92 \pm 13 ; 100$ & $90 \pm 15 ; 96$ & $90 \pm 15 ; 96$ \\
\hline
\end{tabular}

*significant difference $<5 / 5$ vs. $>5$ ( $p<0.01)$

$\dagger$ significant difference $<5$ vs. $>5(p<0.01)$ and 5 vs. $>5(p=0.03)$

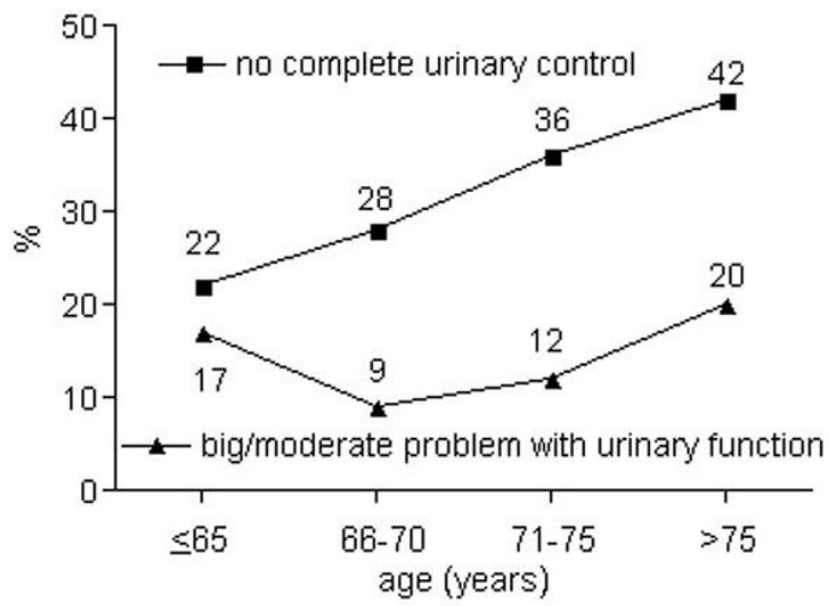

Figure I

Percentage of patients with no complete urinary control $(p<0.0 I)$ and big/moderate problem with urinary function $(p=0.04)$.

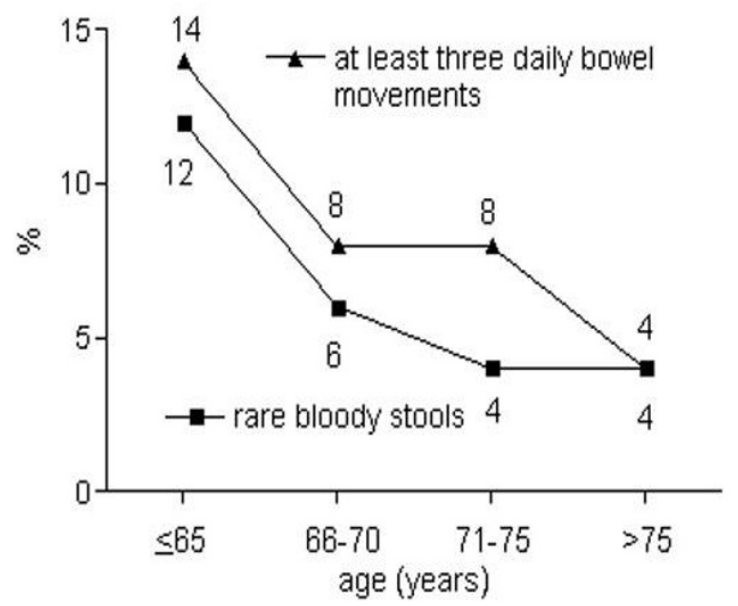

Figure 2

Percentage of patients with at least three daily bowel movements $(p=0.04)$ and at least rare bloody stools $(p=0.02)$. 


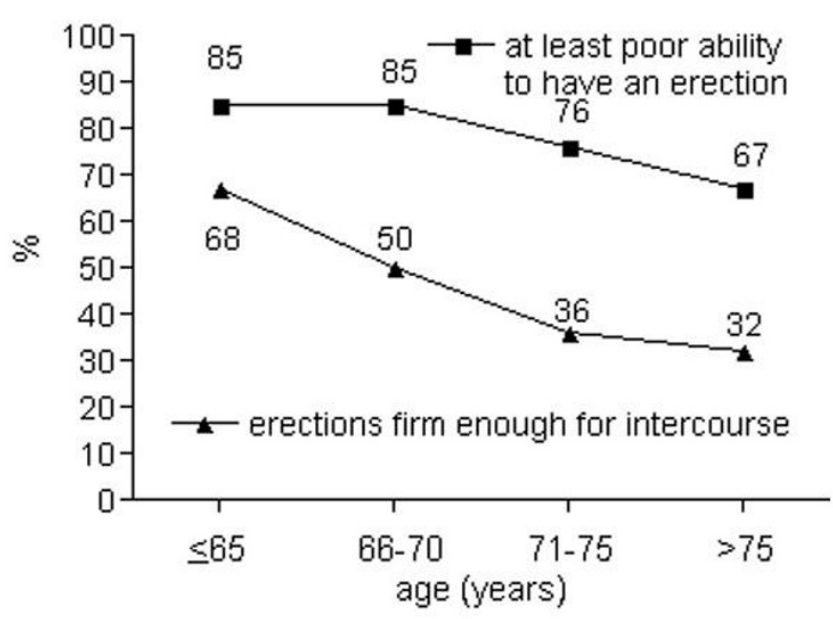

Figure 3

Percentage of patients with at least poor ability to have an erection $(p=0.04)$ and erections firm enough for sexual intercourse $(p<0.01)$.

The multivariate analysis (Table 5) demonstrated an independent influence of both age and comorbidities on incontinence, specifically diabetes on urinary bother (obstructive/irritative symptoms), both age and diabetes on sexual function/bother and both age and comorbidities on hormonal function (contrary effect). The patient groups $\leq 70$ years and $>70$ years had an average age of 65 and 75 years, respectively. Thus, the hazard ratio corresponds on average to the symptom increase between a 65 year old and a 75 year old patient. A CCI $>5$ doubled the probability for individual urinary symptoms, erectile dys-

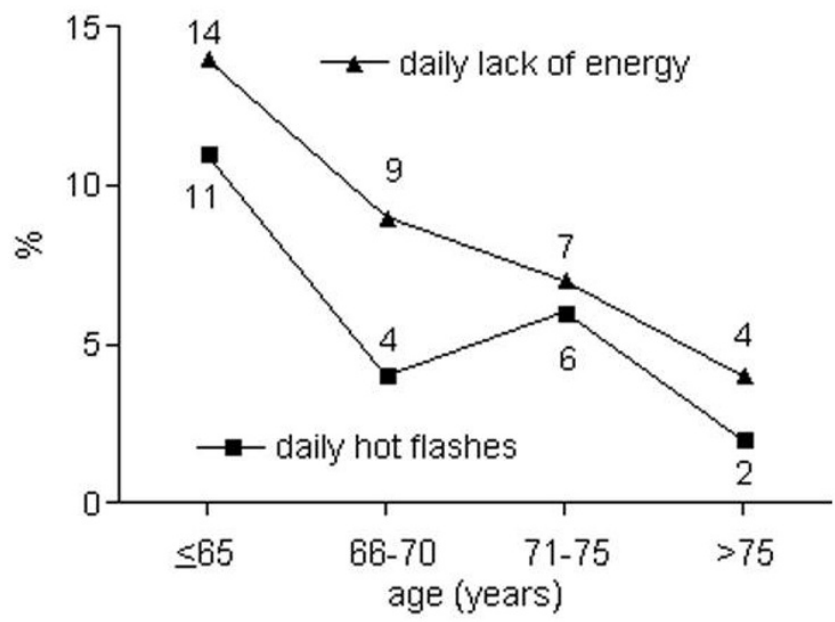

Figure 4

Percentage of patients with daily lack of energy $(p=$ $0.18)$ and daily hot flashes $(p=0.18)$. function or a great/moderate problem with urinary or sexual function overall (Table 6).

Comparing a particular group of prostate cancer patients who were scheduled for a permanent brachytherapy as monotherapy $(\mathrm{n}=69)$ to the remaining patients $(\mathrm{n}=$ 459), a significantly younger patient age (mean 66 vs. 71 years; $\mathrm{p}<0.01$ ) and a smaller portion with comorbidities ( $48 \%$ vs. $64 \%$; $p<0.01$ coronary heart disease in $10 \%$ vs. 24\%: p < 0.01) became evident. HRQOL scores were significantly higher before treatment in the urinary, sexual and hormonal domains with greatest mean differences ( $\mathrm{p}$ $<0.01$ for all) considering urinary continence function/ bother ( 8 points respectively), obstructive/irritative bother/overall urinary bother ( 9 points respectively), and sexual function/bother (18 points respectively).

\section{Discussion}

Patient age has a strong impact on HRQOL for prostate cancer patients before a primary curative treatment. Increasing urinary incontinence, urinary bother, and above all a strongly age-related decreasing sexual function has to be considered. Comparability of studies analyzing incontinence and impotence is often limited by different definitions. Urinary continence can be defined by wearing pads, dripping urine when coughing, any involuntary loss of urine or other definitions [23-25]. In the RTOG/EORTC (Radiation Therapy Oncology Group/European Organization for Research and Treatment of Cancer) grading system, urinary incontinence does not occur at all [26]. LENT SOMA (Late Effects Normal Tissues with Subjective, Objective, Management and Analytic categories) tables consider incontinence in some detail (e.g. grade $1=<$ weekly episodes/occasional use of pads) [27]. HRQOL questionnaires allow an assessment with a higher accuracy from the patient's perspective.

Remarkable differences result between the percentage of patients who retain some ability to have an erection with increasing age and the percentage with erections firm enough for intercourse. Probably the best definition of potency (if only a single definition is used) is the ability to have an erection sufficient for penetration. This ability was found to decline particularly comparing the age groups $\leq 65,66-70$ and 71-75 years. Sexual function scores decreased remarkably between all age groups (mean decrease of 18 points between the age groups $\leq 65$ and $>75$ years). Older patients accept a missing potency easier, so that changes of sexual bother scores were found to be less impressive (mean decrease of only 8 points between the age groups $\leq 65$ and $>75$ years). Improving bother scores for patients with low scores before external beam radiotherapy have been shown in a recently published analysis [20], indicating some adaptation to the sexual problems. 
Table 4: Association of health-related quality of life score decrease with comorbidities (mean \pm standard deviation; only significant differences of at least 5 points presented)

\begin{tabular}{|c|c|c|c|c|}
\hline & comorbidity $\left(n=328 / 178^{*}\right)$ & coronary heart disease $\left(n=119 / 63^{*}\right)$ & diabetes $\left(n=62 / 37^{*}\right)$ & $\operatorname{COPD}(n=49 / 29 *)$ \\
\hline urinary function & - & - & - & - \\
\hline continence function & $5 \pm 2$ & $6 \pm 2$ & $7 \pm 3$ & - \\
\hline irritative/obstructive function & - & - & - & - \\
\hline urinary bother & $6 \pm 2 \dagger$ & $7 \pm 2 \dagger$ & $9 \pm 3 \dagger$ & - \\
\hline continence bother & - & - & - & - \\
\hline irritative/obstructive bother & $5 \pm 2 \dagger$ & $6 \pm 2 \dagger$ & $8 \pm 3 \dagger$ & - \\
\hline sexual function & $9 \pm 3 \dagger$ & - & $16 \pm 4 \dagger$ & - \\
\hline sexual bother & $10 \pm 4$ & - & $18 \pm 6 \dagger$ & - \\
\hline hormonal function & $5 \pm 2 \dagger$ & $7 \pm 2 \dagger$ & - & $5 \pm 3 \dagger$ \\
\hline hormonal bother & $5 \pm 2 \dagger$ & $6 \pm 2 \dagger$ & - & $5 \pm 3 \dagger$ \\
\hline
\end{tabular}

COPD: chronic obstructive pulmonary disease

*patients without a prior hormonal therapy (analysis of sexual and hormonal domains)

$+\mathrm{p}<0.01$

Rectal domain scores have not been found to be agedependent. However, some symptoms differed between the age groups. Older patients tend to have less frequent bowel movements a consequence of declining metabolism and physical activity. Furthermore, the percentage of patients who observed bloody stools is decreasing. It is unclear, if bloody stools are actually not occurring or simply not noticed. An occasional bleeding rate of $12 \%$ in the patient group up to 65 years is remarkable. As rectal bleeding is considered an important sign of proctitis following radiotherapy, this high frequency stresses the importance of recording the presence of bleeding already before treatment. For example, a higher bleeding rate in a patient group with a lower dose to the rectum volume could only be explained by a higher bleeding rate already before treatment in a group of patients after post-prostatectomy radiotherapy [19]. Late rectal bleeding is a key dose-limiting end point in prostate radiotherapy with increasing incidence above a dose of $60 \mathrm{~Gy}$ [28]. In a study by Goldner et al. [29], 52 patients were reported with grade 23 EORTC/RTOG late rectal side effects the reason was rectal bleeding for 50 patients (96\%).

Hormonal function, as defined in the EPIC questionnaire, improved with higher patient ages. Testosterone levels are known to decline with age. Manifestations of testosterone deficiency include depression, irritability, weakness, diminished libido, reduced muscle and bone mass [30].
The results of this study suggest some adaptation to changing hormone levels. As both comorbidities and age (contrary effects on hormonal scores) are considered in the calculation of CCI, no effect of CCI differences was found on hormonal scores.

As recently reported by Bhojani et al. [31], select comorbidities have a very strong effect on urinary function and sexual function. In comparison to the younger patients ( $\leq 65$ years), the incidence of comorbidities was higher with increasing age in our study. Comorbidities have an additional, independent impact on HRQOL. Focusing on specific comorbidities, hypertension the most frequent comorbidity in this population has not been found to influence any of the HRQOL domains. Diabetes mellitus, a disease known to ensue microvascular complications and neuropathy, had the strongest influence on urinary symptoms and, above all, sexuality. Both sexual function and sexual bother scores were affected with a mean decrease of 16 and 18 points, respectively. Diabetes is very well known as a predictor of late radiation morbidity $[32,33]$. In contrast to studies using only various toxicity grading scales [32,33], prospective HRQOL studies help to consider more accurately pre-existing symptoms. Coronary heart disease and independently, chronic obstructive pulmonary disease, were associated with decreased hormonal domain scores. These diagnoses are very well known to reduce normal physical activities. No correla- 
Table 5: Multivariate analysis considering the influence of age ( $>70$ vs. $\leq 70$ years) and comorbidities ( 1. any comorbidity, 2. specific comorbidities) on individual symptoms

\begin{tabular}{|c|c|c|c|c|}
\hline question & risk factor & hazard ratio & $95 \%$ confidence interval & $\mathrm{p}$-value \\
\hline \multirow[t]{3}{*}{ leaking urine $\geq$ once a day } & comorbidity & 2.2 & 1.23 .8 & $<0.01$ \\
\hline & coronary heart disease & 1.7 & 1.02 .9 & 0.06 \\
\hline & diabetes & 1.9 & 1.03 .7 & 0.06 \\
\hline no complete urinary control & age & 1.9 & 1.32 .7 & $<0.01$ \\
\hline \multirow[t]{2}{*}{ great/moderate problem with frequent urination } & comorbidity & 2.0 & 1.23 .3 & $<0.01$ \\
\hline & diabetes & 3.3 & 1.95 .9 & $<0.01$ \\
\hline \multirow[t]{2}{*}{ great/moderate problem with urinary function overall } & comorbidity & 2.2 & 1.23 .9 & $<0.01$ \\
\hline & diabetes & 2.5 & 1.34 .8 & $<0.01$ \\
\hline \multirow[t]{3}{*}{ erections not firm enough for intercourse } & age & 2.8 & 1.74 .7 & $<0.01$ \\
\hline & comorbidity & 1.7 & 1.02 .9 & 0.04 \\
\hline & diabetes & 7.0 & 2.321 & $<0.01$ \\
\hline \multirow[t]{3}{*}{ great/moderate problem with sexual function overall } & age & 1.8 & 1.13 .7 & 0.04 \\
\hline & comorbidity & 1.9 & 1.13 .5 & 0.03 \\
\hline & diabetes & 2.9 & 1.36 .2 & $<0.01$ \\
\hline \multirow[t]{2}{*}{ hot flashes $\geq$ once a day } & comorbidity & 3.5 & 1.012 & 0.05 \\
\hline & COPD & 5.6 & 1.916 & $<0.01$ \\
\hline \multirow[t]{2}{*}{ lack of energy $\geq$ once a day } & age & 0.4 & 0.21 .0 & $<0.05$ \\
\hline & comorbidity & 4.2 & 1.412 & 0.01 \\
\hline great/moderate problem with hot flashes & COPD & 4.5 & 1.513 & $<0.01$ \\
\hline great/moderate problem with lack of energy & comorbidity & 2.7 & 1.16 .4 & 0.03 \\
\hline
\end{tabular}

COPD: chronic obstructive pulmonary disease

Table 6: Hazard ratios for individual symptoms with a Charlson Comorbidity Index of $>5$ vs. $\leq 5$

\begin{tabular}{|c|c|c|c|}
\hline question & hazard ratio & $95 \%$ confidence interval & P-value \\
\hline leaking urine $\geq$ once a day & 2.5 & 1.54 .0 & $<0.01$ \\
\hline no complete urinary control & 1.7 & 1.22 .5 & $<0.01$ \\
\hline great/moderate problem with frequent urination & 2.1 & 1.33 .2 & $<0.01$ \\
\hline great/moderate problem with urinary function overall & 2.1 & 1.33 .2 & $<0.01$ \\
\hline erections not firm enough for intercourse & 2.2 & 1.34 .0 & $<0.01$ \\
\hline great/moderate problem with sexual function overall & 2.2 & 1.23 .8 & $<0.01$ \\
\hline
\end{tabular}

COPD: chronic obstructive pulmonary disease 
tion of comorbidities, similar to the patient age, was found with the rectal domain scores.

\section{Conclusion}

Urinary continence and sexual function are the crucial HRQOL domains with age-related and independently comorbidity-related decreasing scores. Diabetes, not found to increase significantly with age in this population, was found to have the greatest impact on the urinary and above all on the sexual domain. The results need to be considered for the interpretation of studies comparing different primary treatments or longitudinal changes after a curative treatment.

\section{Competing interests}

The authors declare that they have no competing interests.

\section{Authors' contributions}

MP, KF, MJE have made substantial contributions to conception and design; MP and KF have made substantial contributions to acquisition of data; $\mathrm{MP}, \mathrm{KF}, \mathrm{BG}, \mathrm{MDP}$, $\mathrm{BA}, \mathrm{JK}, \mathrm{HB}, \mathrm{GJ}, \mathrm{MJE}$ to analysis and interpretation of data. $\mathrm{MP}$ has been involved in drafting the manuscript. KF, BG, MDP, BA, JK, HB, GJ, MJE revised it critically for important intellectual content. All authors have given final approval of the version to be published.

\section{Acknowledgements}

The study was funded by the research resources of the Department of Radiation Oncology, RWTH Aachen University, Germany. We would like to thank the staff who took care of our patients' needs, and who were involved in gathering, documenting, verifying, forwarding, and processing the clinical data.

\section{References}

I. Ries LA, Eisner MP, Kosary CL, Hankey B, Miller B, Clegg L, Edwards B: SEER cancer statistics review, 19731999 Bethesda: National Cancer Institute; 2002.

2. Jemal A, Siegel R, Ward E, Hao Y, Xu J, Murray T, Thun MJ: Cancer Statistics. CA Cancer J Clin 2008, 58:7I-96.

3. Bill-Axelson A, Holmberg L, Ruutu M, Häggman M, Andersson SO, Bratell S, Spangberg A, Busch C, Nordling S, Garmo H, Palmgren J, Adami HO, Norlen BJ, Johansson JE: Radical prostatectomy versus watchful waiting in early prostate cancer. $N$ Engl J Med 2005, 352:1977-1984.

4. Borchers H, Kirschner-Hermanns R, Brehmer B, Tietze L, Reineke T, Pinkawa M, Eble M, Jakse G: Permanent ${ }^{125}$ I-seed brachytherapy or radical prostatectomy: a prospective comparison considering oncological and quality of life results. BJU Int 2004, 94:805-8II.

5. Litwin MS, Gore JL, Kwan L, Brandeis JM, Lee SP, Withers HR, Reiter RE: Quality of life after surgery, external beam irradiation, or brachytherapy for early-stage prostate cancer. Cancer 2007, 109:2239-2247.

6. Miller DC, Sanda MG, Dunn RL, Montie JE, Pimentel H, Sandler HM, McLaughlin WP, Wie JT: Long-term outcomes among localized prostate cancer survivors: health-related quality-of-life changes after radical prostatectomy, external radiation, and brachytherapy. J Clin Oncol 2005, 23:2772-2280.

7. Soderdahl DW, Davis JW, Schellhammer PF, Given RW, Lynch DF, Shaves M, Burke BL, Fabrizio MD: Prospective longitudinal comparative study of health-related quality of life in patients undergoing invasive treatments for localized prostate cancer. J Endourol 2005, 19:318-326.
8. Buron C, Le Vu B, Cosset J, Pommier P, Peiffert D, Delannes M, Flam T, Guerif S, Salem N, Chauveinc L, Livartowski A: Brachytherapy versus prostatectomy in localized prostate cancer: results of a french multicenter prospective medico-economic study. Int J Radiat Oncol Biol Phys 2007, 67:812-822.

9. Litwin MS, Lubeck DP, Henning JM, Carroll PR: Differences in urologist and patient assessments of health related quality of life in men with prostate cancer. J Urol 1998, I59:1988-1992.

10. Ramsey SC, Zeliadt SB, Hall IJ, Ekwueme DU, Penson DF: On the importance of race, socioeconomic status and comorbidity when evaluating quality of life in men with prostate cancer. J Urol 2007, 177:1992-1999.

II. Wei JT, Dunn RL, Litwin MS, Sandler HM, Sanda MG: Development and validation of the expanded prostate cancer index composite (epic) for comprehensive assessment of healthrelated quality of life in men with prostate cancer. Urology 2000, 56:899-905.

12. Merrick GS, Butler WM, Wallner KE, Galbreath RW, Lief JH: Longterm urinary quality of life after permanent prostate brachytherapy. Int J Radiat Oncol Biol Phys 2003, 56:454-6I.

13. Volz-Sidiropoulou E, Pinkawa M, Fischedick K, Jakse G, Gauggel S, Eble MJ: Factor analysis of the expanded prostate cancer index composite (EPIC) in a patient group after primary (external beam radiotherapy and permanent iodine-I25 brachytherapy) and postoperative radiotherapy for prostate cancer. Curr Urol 2008, 2: 122-129.

14. Pinkawa M, Fischedick K, Asadpour B, Gagel B, Piroth MD, Eble MJ: Low-grade toxicity after conformal radiation therapy for prostate cancer impact of bladder volume. Int J Radiat Oncol Biol Phys 2006, 64:835-84l.

15. Pinkawa M, Fischedick K, Treusacher P, Asadpour B, Gagel B, Piroth $M D$, Borchers $H$, Jakse G, Eble MJ: Dose-volume impact in highdose-rate iridium-192 brachytherapy as a boost to external beam radiotherapy for localized prostate cancer a phase II study. Radiother Oncol 2006, 78:4I-46.

16. Pinkawa M, Fischedick K, Piroth MD, Gagel B, Borchers H, Jakse G, Eble $\mathrm{MJ}$ : Health-related quality of life after permanent interstitial brachytherapy for prostate cancer correlation with postimplant CT scan parameters. Strahlenther Onkol 2006, I 82:660-665.

17. Pinkawa M, Fischedick K, Gagel B, Piroth MD, Borchers H, Jakse G, Eble MJ: Association of neoadjuvant hormonal therapy with adverse health-related quality of life after permanent iodineI 25 brachytherapy for localized prostate cancer. Urology 2006, 68:104-109.

18. Pinkawa M, Fischedick K, Asadpour B, Gagel B, Piroth MD, Nussen S, Eble MJ: Toxicity profile with a large prostate volume after external beam radiotherapy for localized prostate cancer. Int J Radiat Oncol Biol Phys 2008, 70:83-89.

19. Pinkawa M, Fischedick K, Asadpour B, Gagel B, Piroth MD, Holy R, Krenkel $B$, Eble MJ: Health-related quality of life after adjuvant and salvage postoperative radiotherapy for prostate cancer a prospective analysis. Radiother Oncol 2008, 88: I35-139.

20. Pinkawa M, Gagel B, Piroth MD, Fischedick K, Asadpour B, Kehl M, Klotz J, Eble MJ: Erectile dysfunction after external beam radiotherapy for prostate cancer. Eur Urol 2009, 55:227-236.

21. Ososba D, Rodrigues G, Myles J, Zee B, Pater J: Interpreting the significance of changes in health-related quality-of-life scores. J Clin Oncol 1998, I 6: I39-I44.

22. Charlson ME, Pompei P, Ales K, MacKenzie CR: A new method of classifying prognostic comorbidity in longitudinal studies: development and validation. J Chron Dis 1987, 40:373-383.

23. Foote J, Yun S, Leach GE: Postprostatectomy incontinence. Pathophysiology, evaluation and management. Urol Clin North Am 1991, I 8:229-24I.

24. Ponholzer A, Brossner C, Struhal G, Marszalek M, Madersbacher S: Lower urinary tract symptoms, urinary incontinence, sexual function and quality of life after radical prostatectomy and external beam radiation therapy real life experience in Austria. World J Urol 2006, 24:325-330.

25. Standford JL, Feng Z, Hamilton AS, Gilliland FD, Stephenson RA, Eley JW, Albertson PC, Harlan LC, Potosky AL: Urinary and sexual function after radical prostatectomy for clinically localized prostate cancer: the prostate cancer outcome study. JAMA 2000, 283:354-360. 
26. Cox JD, Stetz J, Pajak TF: Toxicity criteria of the Radiation Therapy Oncology Group (RTOG) and the European Organization for Research and Treatment of Cancer (EORTC). Int J Radiat Oncol Biol Phys 1995, 3 I: I 34 I-I 346.

27. Pavy JJ, Denekamp J, Letschert J, Littbrand B, Mornex F, Bernier J, Gonzales-Gonzales D, Horiot JC, Bolla M, Bartelink H: EORTC Late Effects Working Group. Late effects toxicity scoring: the SOMA scale. Radiother Oncol 1995, 35: I I- I5.

28. Brenner DJ: Fractionation and late rectal toxicity. Int J Radiat Oncol Biol Phys 2004, 60:1013-1015.

29. Goldner G, Tomicek B, Becker G, Geinitz H, Wachter S, Zimmermann F, Wachter-Gerstner N, Reibenwein J, Glocker S, Bamberg M, Feldmann H, Potzi R, Molls M, Potter R: Proctitis after externalbeam radiotherapy for prostate cancer classified by Vienna Rectoscopy Score and correlated with EORTC/RTOG score for late rectal toxicity: results of a prospective multicenter study of I 66 patients. Int J Radiat Oncol Biol Phys 2007, 67:78-83.

30. Sternbach H: Age-associated testosterone decline in men: clinical issues for psychiatry. Am J Psychiatry 1998, 155: $1310-1318$

31. Bhojani N, Perrotte P, Jeldres C, Suardi N, Hutterer G, Shariat SF, Karakiewicz PI: The effect of comorbidities and socioeconomic status on sexual and urinary function in men undergoing prostate cancer screening. J Sex Med 2008, 5:668-676.

32. Herold DM, Alexandra LH, Hanks GE: Diabetes mellitus: a predictor for late radiation morbidity. Int J Radiat Oncol Biol Phys 1999, 43:457-479.

33. Schultheiss TE, Lee WR, Hunt MA, Hanlon AL, Peters RS, Hanks GE: Late $\mathbf{G l}$ and $\mathrm{GU}$ complications in the treatment of prostate cancer. Int J Radiat Oncol Biol Phys 1997, 37:3-I I.

\section{Pre-publication history}

The pre-publication history for this paper can be accessed here:

http://www.biomedcentral.com/1471-2407/9/296/pre pub

Publish with Bio Med Central and every scientist can read your work free of charge

"BioMed Central will be the most significant development for disseminating the results of biomedical research in our lifetime. "

Sir Paul Nurse, Cancer Research UK

Your research papers will be:

- available free of charge to the entire biomedical community

- peer reviewed and published immediately upon acceptance

- cited in PubMed and archived on PubMed Central

- yours - you keep the copyright 